\title{
Influence of cervical preflaring on determination of apical file size in the palatal roots of maxillary molars
}

\section{Influência do preparo cervical na determinação da lima anatômica inicial de raízes palatinas de molares superiores}

\begin{abstract}
Purpose: The aim of this study was to investigate the influence of cervical preflaring in determining the initial apical file (IAF) in the palatal roots of maxillary molars, and to determine the morphologic shape of the canal $1 \mathrm{~mm}$ short of the apex.

Methods: After preparing standard access cavities the group 1 received the IAF without cervical preflaring (WCP). In groups 2 to 5, preflaring was performed with Gates-Glidden (GG), Anatomic Endodontics Technology (AET), GT Rotary Files (GT) and LA Axxes (LA), respectively. Each canal was sized using manual K-files, starting with size 08 files, and making passive movements until the WL was reached. File sizes were increased until a binding sensation was felt at the WL. The IAF area and the area of the root canal were measured to verify the percentage occupied by the IAF inside the canal in each sample by SEM. The morphologic shape of the root canal was classified as circular, oval or flattened. Statistical analysis was performed by ANOVA/Tukey test $(P<0.05)$.
\end{abstract}

Results: The decreasing percentages occupied by the IAF inside the canal were: $L A>G T=A E T>G G>$ WCP. The morphologic shape was predominantly oval.

Conclusion: The type of cervical preflaring used interferes in the determination of IAF.

Key words: Cervical preflaring; initial apical file; root canal

\section{Resumo}

Objetivo: O objetivo deste estudo foi avaliar a influência do preparo cervical na determinação da lima anatômica inicial (LAl) em raízes palatinas de molares superiores e determinar a morfologia do canal $1 \mathrm{~mm}$ aquém do ápice.

Metodologia: Após a padronização da cavidade de acesso o grupo 1 recebeu a LAl sem preparo cervical (SPC). Do grupo 2 ao 5 o preparo cervical foi realizado com brocas GatesGlidden (GG), Anatomic Endodontics Technology (AET), GT Rotary Files (GT) e brocas LA Axxes (LA), respectivamente. Os canais foram explorados com lima tipo K inserindo-se passivamente a lima 08 no comprimento de trabalho (CT), e limas de diâmetros sucessivamente maiores até obter a sensação de travamento CT. A área da LAl e a área do canal radicular foram medidas para verificar a porcentagem que o IAI ocupou no interior do canal em cada amostra por meio de MEV. A forma do canal radicular foi classificada em circular, oval e achatada. A análise estatística foi realizada pelo teste ANOVA/Tukey $(P<0,05)$.

Resultados: Diminuição na porcentagen ocupada pela $L A l$ dentro do canal foi: $L A>G T=A E T>G G>S P C$. A morfologia foi predominantemente oval.

Conclusão: $O$ tipo de preparo cervical interfere na determinação da LAI.

Palavras-chave: Preparo cervical; lima anatômica inicial; canal radicular

\author{
Doglas Cecchin a \\ Manoel Damião Sousa-Neto ${ }^{b}$ \\ Jesus Dialma Pécora ${ }^{b}$ \\ Ricardo Gariba Silva b
}

\begin{abstract}
a School of Dentistry, Department of Restorative Dentistry, University of Passo Fundo, Passo Fundo, RS, Brazil

b School of Dentistry, Department of Restorative Dentistry, University of São Paulo, Ribeirão Preto, SP, Brazil.
\end{abstract}

\author{
Correspondence: \\ Doglas Cecchin \\ Universidade de Passo Fundo, Campus 1 \\ Faculdade de Odontologia, BR 285, Km 171 \\ Bairro São José, Caixa Postal 611 \\ 99052-900 \\ Passo Fundo, RS - Brazil \\ E-mail:dgscecchin@yahoo.com.br
}

Received: December 22, 2011

Accepted: January 25, 2012

Conflict of Interests: The authors state that there are no financial and personal conflicts of interest that could have inappropriately influenced their work.

Copyright: (C) 2011 Cechin et al.; licensee EDIPUCRS. This is an Open Access article distributed under the terms of the Creative Commons AttributionNoncommercial-No Derivative Works 3.0 Unported License. 


\section{Introduction}

Although all the stages of endodontic treatment are important, biomechanical preparation of the root canal is one of the operative procedures that requires a great deal of professional skill to ensure that it is adequately shaped and cleaned (1), with emphasis on the apical portion. To clean this effectively, the working length (WL) must be correctly determined and the root canal shaped before it is filled (2).

The extent of apical enlargement is based on the initial apical file (IAF) size, which is determined by the diameter of the first endodontic file that binds to the walls of the root canal at the WL. The main objective is to make the apical stop, to which the main gutta-percha cone will be adapted at the time of filling. In addition, dentin and possibly infected pre-dentin must be removed from the root canal walls. Theoretically, 150 micrometers should be sufficient for this purpose (3).

To determine the IAF size, clinicians have traditionally detected the apical constriction and identified the first file that binds at the WL on the basis of tactile sensitivity. This premise is based on the false belief that the root canal is tight in the apical region and that files can freely reach this point without interference in their trajectory (2).

However, there are factors that may influence this operation. Continuous and progressive dentin formation in the pulp chamber narrows the diameter of the root canal, particularly in the cervical third, and it is one of the negative interferences in this therapeutic procedure (4). As a result of these interferences, using the size of the first file that binds in the apical third to determine the final apical file is not a completely reliable method (2). Therefore, some researchers have indicated that when identifying IAF, previous enlargement of the cervical third of the canal eliminates possible interferences and improves detection of the real anatomical diameter $(5,6)$.

Another important factor to consider in enlarging the apical third of the root canal is the morphologic shape of this region (7). The diversity of morphologic shapes and diameters of root canals make the procedures of shaping and cleaning the walls difficult. The anatomy of the root canal system, dimensions of the canal walls and their final diameters have an influence on the success of treatments after performing enlargement (8). Gani and Visvisian (9) reported the complex anatomy present in the apical region of the root canals of teeth, with emphasis on the maxillary first permanent molar. These authors pointed out that the anatomical aspects of the mentioned tooth make it difficult to perform endodontic therapy, particularly in the vestibular canals.

This study investigated the influence of cervical preflaring with different rotary instruments in determining the IAF in the palatal roots of maxillary molars and to determine the morphologic shape of the canal $1 \mathrm{~mm}$ short of the apex.

\section{Materials and Methods}

\section{Tooth Selection and Preparation}

This study was approved by the Research Ethics Committee of the São Paulo University, Ribeirão Preto,
Brazil. Fifty human maxillary first molars with complete root formation were used in this study. The teeth were stored in $0.1 \%$ thymol solution at $9^{\circ} \mathrm{C}$, and afterwards they were removed and washed for 24 hours before use.

Standard access to the pulp chamber was performed and pulp tissue was removed with a barbed broach (Dentsply Maillefer, Ballaigues, Switzerland), taking care to avoid contact with the root canal walls. The root canal of each tooth was explored using a size 06 K-file (Dentsply Maillefer, Ballaigues, Switzerland) until the apical foramen was reached and the tip of the file was visible. The actual canal length was determined and WL was established by deducting $1 \mathrm{~mm}$.

\section{Preflaring the Coronal and Middle Section of the Root Canals}

The teeth were randomly divided into 5 groups $(n=10)$. In Group 1, the size of the IAF was determined without previous cervical preflaring of the root canal. In Group 2 , cervical and middle third preflaring of the canal was performed with Gates-Glidden burs (Dentsply Maillefer, Ballaigues, Switzerland) numbers 90 and 110, used in this order, until each of them resisted further penetration. Anatomic Endodontic Technology files (Ultradent Products, South Jordan, Utah) Shaping 1, Shaping C, Shaping 2 and Shaping 3, were used in this order, $5 \mathrm{~mm}$ short of the WL in Group 3. In Group 4, cervical and middle third preflaring was performed with the Ni-Ti GT Rotary Files (Dentsply Maillefer, Ballaigues, Switzerland) 20/.06, 20/.08, 20/.10 and 20/.12, used in this order, $5 \mathrm{~mm}$ short of the WL. In Group 5, titanium-nitrate treated stainless steel LA Axxess burs (SybronEndo, Glendora, CA, USA) 20/.06 and 30/.06 were used in this order in cervical and middle third preflaring, until each of them resisted further penetration.

The GT files were used with the TC 3000 motor (Nouvag, Goldach, Switzerland), at $300 \mathrm{rpm}$. The Gates-Glidden and LA Axxess burs were coupled to a low speed handpiece (Kavo, Joinvile, SC, Brazil) operating at 5,000 rpm. The files of the AET system were used with the Endo-Eze motor (Ultradent Products, South Jordan, Utah) at 1,500 rpm. Before using each file, and at each change of file, the canal was irrigated with $2 \mathrm{ml}$ of $2,5 \% \mathrm{NaOCl}$ allowing the canal to be filled with irrigant solution when it received the action of the file. Next, the canal was irrigated with $2 \mathrm{ml}$ of distilled water and the IAF was determined.

\section{Determination of IAF}

The IAF was determined using a type K file (Dentsply Maillefer, Ballaigues, Switzerland), $25 \mathrm{~mm}$-long. The files were introduced into the root canal with rotary movements of $90^{\circ}$ in the clockwise and anti-clockwise directions. File sizes were increased until a binding sensation was felt at the WL, and the instrument size was recorded for each tooth. The file handles files were painted black to prevent identification, thus the operator was blind to the file size used until a binding sensation was felt at the WL. 
After selecting and adapting all the endodontic files to the WL, thus determining IAF of the root canals in different groups, the files were fixed in the root canal entrances with a drop of ethyl cyanoacrylate adhesive (SuperBonder, Loctite, São Paulo, SP, Brazil). All the roots were sectioned with a double-faced diamond disk (KG Soresen, São Paulo, Brazil) $10 \mathrm{~mm}$ from the root apex. Next, the root apexes were sectioned transversally with a diamond disk one millimeter short of their ends. The apical region was observed by scanning electron microscopy (100x magnification) and the images were digitalized.

From the images obtained, the IAF area and root canal area were measured by computer using the UTHSCSA ImageTool program (developed at the University of Texas Health Science Centre at San Antonio, Texas, USA and available on the Internet by anonymous FTP from ftp:// maxrad6.uthscsa.edu). With these measurements, the percentage occupied by the IAF within the root canal was assessed by the equation: ØIAI/ØC x 100, where ØIAI is the area occupied by the IAF, and $\varnothing \mathrm{C}$ is the total area of the root canal. This value was used to show which type of cervical enlargement promoted the best adaptation of the IAF to the root canal, and consequently, most faithfully determined the anatomic diameter of the root canal.

The data were submitted to the analysis of variance to assess the effect of cervical preflaring in the area occupied by the IAF at WL. The Tukey test showed groups which presented a statistically significant difference among them. A level of significance of 5\% was considered.

\section{Determination of Morphologic Shape}

The morphologic shape of the root canals was classified according to Gani and Visvisian (9) as: circular (when both diameters, bucco-lingual and mesio-distal, were the same), oval (when the largest diameter, bucco-lingual or mesiodistal, exceeded the smallest by up to one radius) and flattened (when the largest diameter, bucco-lingual or mesio-distal, exceeded the smallest by more than one radius). Since the radius is half of the diameter of a circumference, that is, the distance from the center to any point of the circumference, this measurement was performed in the center of the root canals up to their extension (in the bucco-lingual and mesiodistal direction) for later comparison with the bucco-lingual and mesio-distal diameters.

\section{Results}

The area occupied by the IAF with regard to the canal area at WL of each group is shown in percentage in Table 1.

Table 1. IAF area with regards to the canal area. Data in percentage

\begin{tabular}{lc}
\hline \multicolumn{1}{c}{ Preflaring technique } & $\begin{array}{c}\text { Palatal } \\
\text { (mean } \pm \text { standard deviation) }\end{array}$ \\
\hline No preflaring & $21.43 \pm 2.79^{\mathrm{d}}$ \\
Gates-Glidden drills & $35.70 \pm 7.62^{\mathrm{c}}$ \\
AET & $51.98 \pm 10.67^{\mathrm{b}}$ \\
GT Rotary Files & $49.50 \pm 10.05^{\mathrm{b}}$ \\
LA Axxess burs & $66.55 \pm 11.40^{\circ}$ \\
\hline
\end{tabular}

Means followed by different letters to indicate statistically significant differences $(P<.05)$.

The Tukey test showed that in Group 5, in which cervical preflaring was performed with LA Axxess burs, the IAF occupied largest area inside the root canal among the studied groups, with a statistically significant difference from the others. Group 3 and Group 4, preflared with the AET files and GT respectively, constituted a group apart, since they did
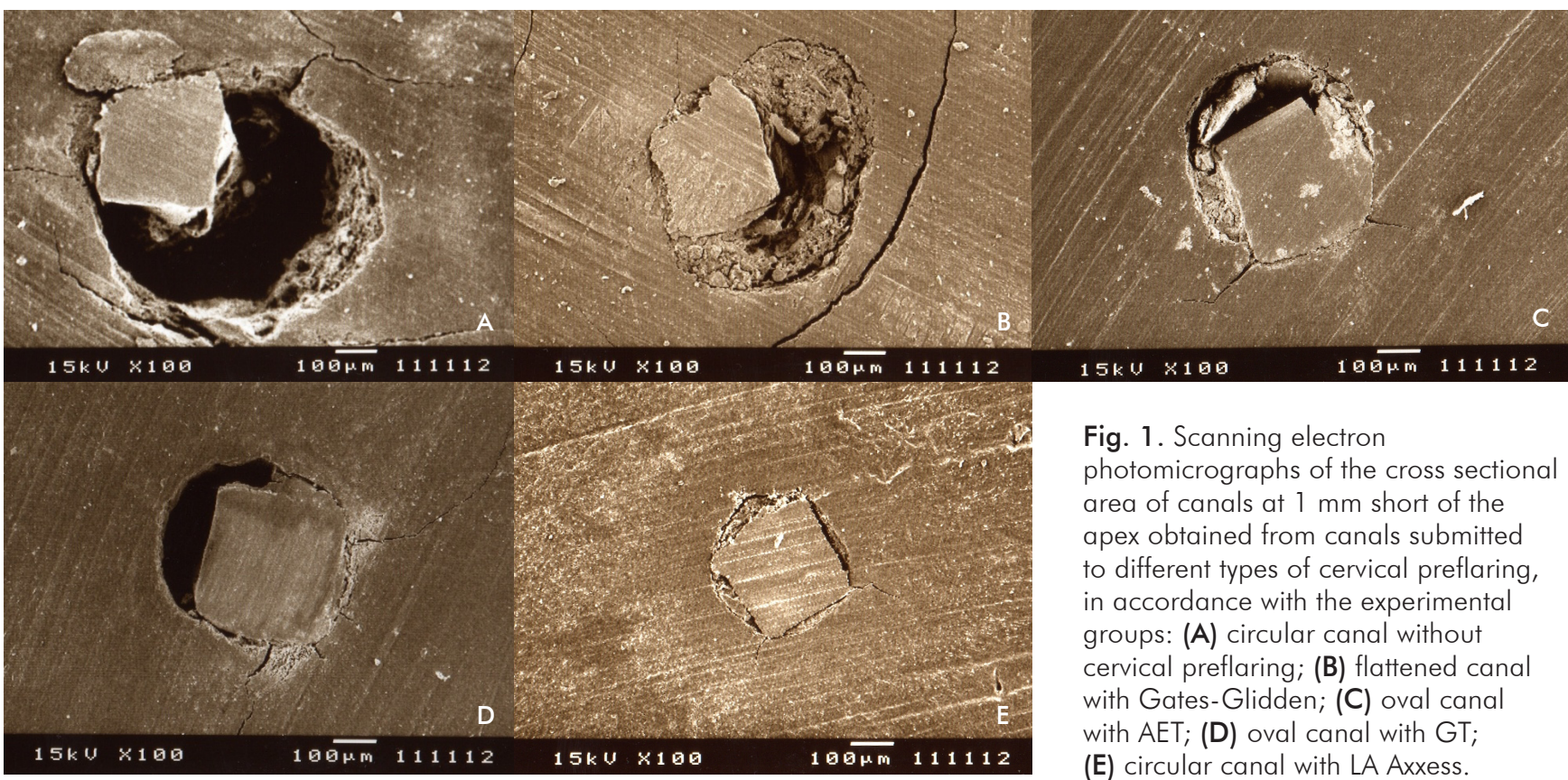

Fig. 1. Scanning electron photomicrographs of the cross sectional area of canals at $1 \mathrm{~mm}$ short of the apex obtained from canals submitted to different types of cervical preflaring, in accordance with the experimental groups: (A) circular canal without cervical preflaring; (B) flattened canal with Gates-Glidden; (C) oval canal with AET; (D) oval canal with GT; (E) circular canal with LA Axxess. 
not present any statistically significant differences between them and their behavior was statistically different from that of other groups, in which IAF occupied the second largest area of the root canal among the studied groups. The second smallest areas occupied by the IAF were represented by the samples that received previous cervical preflaring with Gates-Glidden burs, with a statistically significant difference from the other groups. The smallest areas occupied by the IAF were represented by the samples that did not receive previous cervical enlargement (Group 1), with a statistically significant difference from the other groups (Fig. 1).

The Table 2 shows the file sizes that bound at WL with their respective cervical preflaring. The morphologic shape of the root canal in the apical region $1 \mathrm{~mm}$ short of the apex was predominantly oval for the palatal canal (Table 3 and Fig. 1).

Table 2. File sizes utilized with IAF

\begin{tabular}{lc}
\hline \multicolumn{1}{c}{ Preflaring technique } & Palatal \\
\hline No preflaring & $29.50 \pm 3.68$ \\
Gates-Glidden drills & $32.50 \pm 4.24$ \\
AET & $35.00 \pm 5.27$ \\
GT Rotary Files & $36.00 \pm 3.94$ \\
LA Axxess burs & $41.00 \pm 3.16$ \\
\hline
\end{tabular}

Table 3. Frequency (absolute and relative) of the morphologic shape of the root canals (number of canals)

\begin{tabular}{ccccc}
\hline Canal & Circular & Oval & Flattened & Total of canals \\
\hline Palatal & $19(38 \%)$ & $20(40 \%)$ & $11(22 \%)$ & $50(100 \%)$ \\
\hline
\end{tabular}

\section{Discussion}

Determining the IAF is one of the most critical aspects when performing endodontic treatment, particularly in curved canals. Studies conducted with the purpose of establishing the most adequate parameter for biomechanical preparation of the apical third have shown that there is a direct relationship between the preparation performed in the cervical third of the root canal and the most exact determination of the IAF $(5,6)$. In this study, the removal of cervical interferences allowed the insertion of larger diameter files that bind at the WL after previous preflaring of the cervical and middle thirds.

Statistical analysis of the results obtained in this study showed differences among the different experimental groups. Group 5, in which previous enlargement was performed with LA Axxess burs, presented the largest area occupied by the IAF inside the root canal at WL in the mesiobuccal, distobuccal and palatal canals. They can be attributed to the characteristics of the LAAxxess files, such as the metal alloy property and "modus operandi", besides its taper (0.06), inactive tip and design of the active part (flute design), which allowed removal of all cervical interferences without the occurrence of deviations or perforations (5).
Group 3 and Group 4, where AET and GT Rotary Files were used respectively, presented the second largest area occupied by the IAF inside the root canal at WL, without any statistically significant differences and differing from the other experimental groups in the cervical preflaring of mesiobuccal, distobuccal and palatal canals. According to Buchanan (10), GT files have the advantage of being similar in shape to the root canal morphology, providing simpler and more efficient preparation, which possibly enabled greater removal of cervical interferences. The AET files are used with alternating movements by oscillation at $30^{\circ}$, for the purpose of preflaring the cervical and middle thirds of the root canal (11). The end of the active part of these files is rigid and they are flexible at the tip, which allows one to guide their direction during preparation. This probably helped to remove the cervical interferences.

The Gates-Glidden burs, used in Group 2, provided direct access to two thirds of the root canal, reducing contact areas of the file in these regions. However, these files do not guarantee that the type $\mathrm{K}$ files, which bind at WL, would indicate the real anatomic diameter.

Furthermore, in this experiment, the group in which the type $\mathrm{K}$ files were inserted into the root canal without previous enlargement of the cervical and middle thirds (Group 1), presented the smallest areas occupied by the IAF inside the root canal at the WL. This confirmation reinforces the presupposition that in the majority of the cases, determination of the IAF before previous cervical preflaring does not reflect the real diameter of the root canal.

Sometimes, the file used to probe the root canal, particularly the molars, is used to measure the IAF. However, this technique does not measure the diameter of the root apexes with precision, as these mainly have an oval or flattened shape. Wu et al. (2) observed that in $75 \%$ of cases, the file came into contact with only one of the apical third walls, and in the remaining $25 \%$, there was no file contact with any of the apical walls. In $90 \%$ of the canals, the diameter of the initial file was smaller than the apical diameter of the canal. Consequently, using the first file to measure the size of the root canal apex and using it as a guide for apical enlargement is not a reliable method.

In this study, it was emphasized that the best adaptation of the IAF to the root canal wall was achieved in the group enlarged with LA Axxess and in this group, the mean apical anatomic diameter of the root canal corresponded to the type $\mathrm{K}$ file \#40. These files may represent the IAF for the palatal roots of the maxillary first molars. These results are contrary to the observations of Torabinejad (3) who recommended the smallest possible enlargement of the apical third of root canals, up to the maximum diameter corresponding to the type $\mathrm{K}$ file $\# 25$ or $\# 30$, for these teeth.

Thus, the concept of debriding the canal with three files larger than the one that binds at the WL must be reviewed, because it may be ineffective, and may lead to the nondebridement of the canal walls when cervical preflaring is not adequately performed. Many studies have shown that root canal cleaning and shaping are not adequate procedures $(12,13)$. 
This may be attributed to the canal diameter being greater than the file diameter, thus biomechanical preparation is not capable of cleaning the entire root canal wall.

Preparation of the apical third must provide adequate cleaning, and also allow a circular shape to be obtained for later adaptation of the cone and filling cement (13). It is more difficult to attain these goals in oval and flattened canals, because a greater quantity of dentinal structure will have to be removed in order to achieve this shape, thus diminishing the thickness of the walls, which may lead to perforation or fracture (14).

Several studies have shown that cleaning tight, curved and flattened canals is not easily achieved $(15,16)$, indicating that the anatomic variations are also important factors to take into consideration when performing endodontic treatment, and the apical three millimeters of the root canal are considered the critical area in endodontic treatment (17).

Therefore, after debridement, in some oval and flattened root canals, the walls may not be prepared, irrespective of the debridement technique, leaving smear layer, debris and unprepared root canal walls $(8,16)$. This complex anatomy may be considered one of the main challenges in controlling root canal infection, because the pulp tissue as well as the root dentin may conceal toxins and microorganisms, compromising the final result of endodontic treatment (18).

When the apical portion of the root canal has an oval or flattened shape, determining the first file that binds at the WL does not usually reflect the real anatomic diameter of the root canal. Thus, preparation of the apical portion using three files with successively larger diameters is inadequate, because the infected dentin may not be eliminated (14). Therefore, the apical stop created during biomechanical preparation can be located in a certain area of the apical portion of the canals that do not have a circular shape, by the lack of action of the files on the root canal walls (19). Thus, the possibility of apical leakage occurring and consequent failure of the endodontic treatment becomes more probable.

According to Usman et al. (20) when using the debridement technique only, it is impossible to perform complete cleaning of oval and flat-shaped canals. This fact was emphasized by $\mathrm{Wu}$ and Wesselink (21) and by Rödig et al. (22), who showed that the use of balanced force of manual debridement or the use of NiTi files does not allow complete circumferential preparation. The files create a circular salience in the canal, leaving areas without preflaring and filled with a smear layer and debris. Other studie assessed the efficiency of five NiTi rotary systems in cleaning the canal. It was discovered that all the techniques left $35 \%$ or more of untouched surfaces in the canal (23). The use of endodontic irrigant solutions and ultrasound agitation (24), or even the association of solutions, are ways that may improve the cleaning of roots that have a complex anatomy (25).

Taking into account that the major purposes of endodontic therapy is the cleaning and shaping of root canals, and considering that the first shortcoming to be overcome is performing an accurate determination of the file from which the canal should be instrumented, it is important that current concepts and techniques in Endodontics are reviewed to widen the scope of root canal treatment and offer new perspectives and parameters to make these goals achievable.

According to the methodology proposed and based on the findings of this study, the following conclusions may be drawn: previous enlargement of the cervical and middle thirds of the root canal with rotary and oscillatory files allows more accurate determination of the IAF; the type of enlargement used interferes in determining the IAF, and the group that showed the best adaptation of this file to the root canal walls, among all the canals assessed, was that one enlarged with LA Axxess burs; none of the types of preflaring allowed perfect identification of the anatomic diameter of the root canals by means of the IAF; and the shapes of the root canals were found to be predominantly oval for the palatal canal.

\section{Acknowledgements}

This research was supported by Coordenação de Aperfeiçoamento de Pessoal de Nível Superior (CAPES).

\section{References}

1. Versümer J, Hüllsmann M, Schäfers F. A comparative study of root canal preparation using ProFile .04 and Lightspeed rotary Ni-Ti instruments. Int Endod J 2002;35:37-46.

2. Wu MK, Barkis D, Roris A, Wesselink PR. Does the first file to bind correspond to the diameter of the canal in the apical region? Int Endod J 2002; 35: 264-7.

3. Torabinejad M. Passive step-back technique. Oral Surg Oral Med Oral Pathol 1994; 77:398-401

4. Baugh $D$, Wallace J. The role of apical instrumentation in root canal treatment: a review of the literature. J Endod 2005;31:333-40.

5. Pécora JD, Capelli A, Guerisoli DMZ, Spanó JCE, Estrela C. Influence of cervical preflaring on apical file determination. Int Endod J 2005;38:430-5.

6. Tennert C, Herbert J, Altenburger MJ, Wrbas KT. The effect of cervical preflaring using different rotary nickel-titanium systems on the accuracy of apical file size determination. J Endod 2010;36:1669-72.

7. Martos J, Lubian C, Silveira LF, Suita de Castro LA, Ferrer Luque CM. Morphologic analysis of the root apex in human teeth. J Endod 2010;36:664-7.

8. Grande NM, Plotino G, Pecci R, Bedini R, Pameijer CH, Somma F. Micro-computarized tomographic analysis of radicular and canal morphology of premolar with long canal oval. Oral Surg Oral Med Oral Pathol Oral Radiol Endod 2008;106:e70-e76. 
9. Gani O, Visvisian C. Apical canal diameter in the first upper molar at various ages. J Endod 1999;25:689-91.

10. Buchanan LS. Prosystem GT: design, technique, and advantages. Endodontic Topics 2005; 10:168-75.

11. Ritano F. Anatomic Endodontic Technology (AET) - a crown down root canal preparation technique: basic concepts, operative procedure and instruments. Int Endod J 2005;38: 575-87.

12. Wu MK, Wesselink PR. Efficacy of three techniques in cleaning the apical portion of curved root canals. Oral Surg Oral Med Oral Pathol Oral Radiol Endod 1995;79:492-6.

13. Weiger R, Bartha T, Kalwitzki M, Löst C. A clinical method to determine the optimal apical preparation size. Part I. Oral Surg Oral Med Oral Pathol Oral Radiol Endod 2006;102:686-91.

14. Wu MK, Roris A, Barkis D, Wesselink PR. Prevalence and extent of long oval canals in the apical third. Oral Surg Oral Med Oral Pathol Oral Radiol Endod 2000;89:739-43.

15. Siqueira JF, Araúio MC, Garcia PF, Fraga RC, Dantas CJ. Histological evaluation of the effectiveness of five instrumentation techniques for cleaning the apical third of root canals. J Endod 1997;23:499-502.

16. Barbizam JVB, Fariniuk LF, Marchesan MA, Pécora JD, Sousa-Neto MD. Effectiveness of manual and rotary instrumentation techniques for cleaning flattened root canals. J Endod 2002;28:365-6.

17. Simon JHS. The apex: how critical is it? Gen Dent 1994;42:330-4.

18. Hülsmann M, Peters OA, Dummer PMH. Mechanical preparation of root canals: shaping goals, techniques and means. Endodontics Topics 2005; 10:30-76.

19. Kastakova A, Wu M, Wesselink P. An in vitro experiment on the effect of an attempt to create an apical matrix during root canal preparation on coronal leakage and material extrusion. Oral Surg Oral Med Oral Pathol Oral Radiol Endod 2001;91:462-7.

20. Usman N, Baumgartner JC, Marshall JG. Influence of instrument size on root canal debridement. J Endod 2004;30:1 10-2.

21. Wu MK, Wesselink PR. A primary observation on the preparation and obturation of oval canals. Int Endod J 2001;34:137-41.

22. Rödig T, Hülsmann M, Mühge M, Schäfer F. Quality of preparation of oval distal root canals in mandibular molars using nickel-titanium instruments. Int Endod J 2002;35:919-28.

23. Peters $\mathrm{OA}$, Peters $\mathrm{Cl}$, Schnenberger K, Barbakaw F. ProTaper rotary root canal preparation: assessment of torque force in relation to canal anatomy. Int Endod J 2003;36:93-9.

24. Plotino G, Pameijer CH, Grande NM, Somma F. Ultrasonics in endodontics-a review of the literature. J Endod 2007;33:81-95.

25. Arruda M, Arruda MP, Carvalho-Júnior JR, Souza-Filho FJ, Sousa-Neto MD, Freitas GC. Removal of the smear layer from flattened canals using different chemical substances. Gen Dent 2007;55:523-6. 